\section{CardioRenal Medicine}

\title{
Very Low Density Lipoprotein Metabolism in Patients with Chronic Kidney Disease
}

\author{
Xuewen Wang ${ }^{a}$ Sharina Belania,b Daniel W. Coyne ${ }^{b}$ \\ Elisa Fabbrini $^{a}$ Dominic N. Reeds ${ }^{a}$ Bruce W. Patterson ${ }^{a}$ \\ Bettina Mittendorfer ${ }^{a}$ Samuel Klein ${ }^{a}$ \\ ${ }^{a}$ Center for Human Nutrition, and ${ }^{\mathrm{b}}$ Renal Division, Department of Internal Medicine, \\ Washington University School of Medicine, St. Louis, Mo., USA
}

\section{Key Words}

Isotope tracer $\cdot$ Lipoprotein $\cdot$ Metabolism · Renal failure

\begin{abstract}
Background: Hypertriglyceridemia is a common metabolic complication of chronic kidney disease (CKD) and an important risk factor for coronary heart disease in this patient population. The mechanisms responsible for the development of hypertriglyceridemia in subjects with CKD are not clear. Methods: We studied very low density lipoprotein triglyceride (VLDL-TG) and VLDL-apolipoprotein B-100 (VLDL-apoB-100) kinetics in vivo in 6 subjects with non-dialysis-dependent CKD (CKD-ND), 6 subjects with CKD treated with peritoneal dialysis (CKD-PD) and 24 sex-, age- and body mass index-matched control subjects with normal renal function (12 control subjects each matched with the CKD-ND and CKD-PD group, respectively). Results: The secretion rates of VLDL-TG and VLDL-apoB-100 into plasma were not different between CKD-ND or CKD-PD and their respective control groups. The mean residence times of VLDL-TG and VLDLapoB-100 in plasma, which represents the time VLDL-TG and VLDL-apoB-100 spend in the circulation after secretion by the liver, tended to be greater in subjects with CKD-ND than in control subjects ( $222 \pm 38$ vs. $143 \pm 21 \mathrm{~min}, \mathrm{p}=0.07$, and $352 \pm 102$ vs. $200 \pm 20 \mathrm{~min}, \mathrm{p}=0.06$, respectively) and were about two-fold greater in subjects with CKD-PD compared with their control group ( $248 \pm 51$ vs. $143 \pm 21$ min and $526 \pm 116$ vs. $182 \pm 16$ min, respectively; both $p \leq$ 0.01). Conclusion: Impaired plasma clearance of VLDL-TG and VLDL-apoB-100 is the major abnormality associated with hypertriglyceridemia in patients with either CKD-ND or CKD-PD.
\end{abstract}




\section{CardioRenal Medicine}

Cardiorenal Med 2012;2:57-65

DOI: $10.1159 / 000335509$ www.karger.com/crm

Wang et al.: VLDL Metabolism and Renal Failure

\section{Introduction}

Hypertriglyceridemia is a major metabolic abnormality associated with chronic kidney disease (CKD) [1], and is likely an important contributor to the marked increase in mortality from coronary heart disease observed in this patient population $[1,2]$. The deterioration in renal function is associated with increases in serum triglyceride (TG) and very low density lipoprotein-apolipoprotein B-100 (VLDL-apoB-100) concentrations that are most pronounced in patients with renal failure undergoing dialysis [3]. The exact mechanisms responsible for the development of hypertriglyceridemia in patients with CKD are not clear because of data from different studies reporting either impaired catabolism alone or a combination of impaired catabolism and increased secretion of VLDL-apoB-100 and VLDL-TG from the liver [4-9]. The reason(s) for the discrepancies between studies is not known, but could be related to differences in the severity of kidney disease and whether dialysis was used to treat renal failure among study populations. We are aware of only one study that compared subjects with renal disease who were treated conservatively with those treated with dialysis [9]. The results from this study indicate that dialysis was associated with an increased hepatic VLDL-apoB-100 secretion rate and a reduced intravascular VLDL-apoB-100 catabolic rate; however, VLDL-TG kinetics were not evaluated.

The purpose of the present study was to evaluate VLDL-TG and VLDL-apoB-100 kinetics in patients with CKD who do not require dialysis and patients with more severe renal dysfunction who require dialysis therapy. We hypothesized that patients with CKD who do not need dialysis therapy would demonstrate impaired plasma clearance of VLDL-TG and VLDL-apoB-100, whereas patients who require dialysis would demonstrate both impaired plasma clearance and increased hepatic secretion of VLDL-TG and VLDL-apoB-100. Stable isotopically labeled tracer infusions, in conjunction with mathematical modeling, were used to assess plasma VLDL-TG and VLDL-apoB-100 kinetics in subjects with CKD and sex-, ageand body mass index (BMI)-matched control subjects with normal renal function.

\section{Subjects and Methods}

\section{Subjects}

Four groups of subjects participated in this study: (1) 6 subjects with CKD who did not require dialysis (non-dialysis-dependent CKD, CKD-ND); (2) 6 subjects with CKD which led to renal failure and required dialysis (CKD treated with peritoneal dialysis, CKD-PD); (3) 12 sex-, age-, and BMI-matched control subjects for group 1 (CKD-ND subjects), and (4) 12 sex-, age-, and BMI-matched control subjects for group 2 (CKD-PD subjects). CKD-ND subjects were included if they had stage 3 or 4 CKD and were not being treated with dialysis or expected to require dialysis therapy within the next 6 months. Subjects with CKD-PD were included if they were being treated with continuous ambulatory peritoneal or automated peritoneal dialysis for $\geq 6$ months, and the delivered dialysis dose was considered adequate (actual Kt/V was $2.7 \pm 0.2$ per week; mean \pm SEM) as determined within 3 months prior to the study. The causes for CKD were as follows: hypertension ( $\mathrm{n}=3$; 2 CKD-ND, 1 CKD-PD), polycystic kidney disease (2 CKD-ND), glomerulonephritis ( $\mathrm{n}=3$; membranoproliferative glomerulonephritis: 1 CKD-ND, 1 CKDPD; IgM glomerulonephritis: 1 CKD-PD), Alport syndrome (1 CKD-PD), multiple renal stones and surgeries (1 CKD-PD), and unknown causes ( $\mathrm{n}=2$; 1 CKD-ND, 1 CKD-PD). All subjects completed a comprehensive medical evaluation, including a medical history, a physical examination, a resting 12-lead electrocardiogram, standard blood and urine tests, and an oral glucose tolerance test. Potential participants with severe hypertriglyceridemia (serum TG concentration $>300 \mathrm{mg} / \mathrm{dl}$ ), impaired oral glucose tolerance, diabetes, peritonitis within the last 3 months, and those taking lipid-lowering medications were excluded from this study. All subjects were weight stable $(<2 \%$ change in body weight) and sedentary (regular exercise $<1 \mathrm{~h}$ /week) for $\geq 2$ months and provided written informed consent before participation in the study, which was approved by the Human Research Protection Office at Washington University School of Medicine in St. Louis, Mo., USA. 


\section{CardioRenal Medicine}

\begin{tabular}{l|l}
\hline \multicolumn{2}{l}{ Cardiorenal Med 2012;2:57-65 } \\
\hline DOI: 10.1159/000335509 & $\begin{array}{l}\text { O 2012 S. Karger AG, Basel } \\
\text { www.karger.com/crm }\end{array}$ \\
\hline
\end{tabular}

Wang et al.: VLDL Metabolism and Renal Failure

\section{Metabolic Study}

Subjects were admitted to the Clinical Research Unit in the afternoon, after having been instructed to abstain from exercise and alcohol consumption for 3 days. Whole-body fat mass and fat-free mass were determined by using dual-energy X-ray absorptiometry (Hologic Delphi W, Waltham, Mass., USA). At 19:00 h, they consumed a standard meal containing $12 \mathrm{kcal} / \mathrm{kg}$ fat-free mass, and then fasted (except for water) until completion of the study the next day. Subjects with CKD-PD drained their dialysate bag at 22:00 $\mathrm{h}$ and abstained from further dialysis until completion of the metabolic study protocol the next day.

The following morning, at approximately $05: 30 \mathrm{~h}$, a catheter was inserted into a forearm vein to administer stable isotopically labeled tracers and a second catheter was inserted into a contralateral hand vein, which was heated to $55^{\circ} \mathrm{C}$ by using a thermostatically controlled box to obtain arterialized blood samples. Immediately before the administration of labeled tracers (all purchased from Cambridge Isotope Laboratories, Andover, Mass., USA), blood samples were obtained to determine plasma substrate and insulin concentrations and background glycerol, palmitate, and leucine tracer-to-tracee ratios (TTR) in plasma and in VLDL-TG and VLDL-apoB-100. At $07: 00 \mathrm{~h}$, a bolus of $\left[1,1,2,3,3-{ }^{2} \mathrm{H}_{5}\right]$ glycerol $(75 \mu \mathrm{mol} / \mathrm{kg}$ body weight), dissolved in $0.9 \% \mathrm{NaCl}$ solution, was administered through the catheter in the forearm vein, followed by constant infusions of $\left[2,2-{ }^{2} \mathrm{H}_{2}\right]$ palmitate $\left(0.03 \mu \mathrm{mol} / \mathrm{kg}\right.$ body weight $\left.\cdot \mathrm{min}^{-1}\right)$, dissolved in $25 \%$ human albumin solution, and $\left[5,5,5-{ }^{2} \mathrm{H}_{3}\right]$ leucine $\left(0.06 \mu \mathrm{mol} / \mathrm{kg}\right.$ body weight $\cdot \mathrm{min}^{-1}$; prime: $4.2 \mu \mathrm{mol} / \mathrm{kg}$ body weight) dissolved in $0.9 \% \mathrm{NaCl}$ solution, for $12 \mathrm{~h}$. Blood samples were obtained at $5,15,30,60,90$, $120 \mathrm{~min}$ and then every hour for $10 \mathrm{~h}$ to determine glycerol, palmitate, and leucine TTRs in plasma and in VLDL-TG and VLDL-apoB-100.

Blood samples were collected in chilled tubes containing EDTA to determine substrate concentrations, and EDTA plus trasylol to determine insulin concentrations. Samples were immediately submerged in ice, and plasma was separated by low speed centrifugation within $30 \mathrm{~min}$ of collection. Aliquots of plasma were refrigerated at $4^{\circ} \mathrm{C}$ for subsequent isolation of VLDL; the remaining plasma was stored at $-80^{\circ} \mathrm{C}$ until final processing.

The VLDL fraction was isolated from plasma by ultracentrifugation (Optima LE-80K preparative ultracentrifuge equipped with a type 50.4 Ti rotor, Beckman Instruments) [10, 11]. Aliquots of the VLDL fraction were used for measuring VLDL-apoB-100 concentration immediately after collection; the remaining samples were stored at $-80^{\circ} \mathrm{C}$ until further processing and analyses.

Plasma glucose concentration was determined by using an automated glucose analyzer (YSI 2300 STAT plus; Yellow Springs Instrument Co., Yellow Springs, Ohio, USA). Plasma insulin concentration was measured by using radioimmunoassay (Linco Research, St. Charles, Mo., USA). Plasma concentrations of total TG, total cholesterol, high density lipoprotein (HDL) cholesterol and LDL cholesterol were measured by standard hospital laboratory methods by using a Hitachi 917 autoanalyzer (Hitachi, Tokyo, Japan). Plasma free fatty acid concentrations were quantified by gas chromatography (Hewlett-Packard 5890-II, Palo Alto, Calif., USA) after adding heptadecanoic acid to plasma as an internal standard [12]. Plasma apoB-100 and VLDL-apoB-100 concentrations were measured by using a turbidimetric immunoassay (Wako Pure Chemical Industries Ltd., Osaka, Japan). Plasma VLDL-TG concentration was measured by using a colorimetric enzymatic kit (Sigma-Aldrich Co., St. Louis, Mo., USA).

Plasma free glycerol, palmitate, and leucine TTRs, the TTRs of glycerol and palmitate in VLDL-TG, and the TTR of leucine in VLDL-apoB-100 were determined by using gas chromatography-mass spectrometry (GC-MS; MSD 5973 System, Hewlett-Packard) as previously described [10-16]. Plasma free palmitate and palmitate in VLDL-TG were analyzed as methylesters. The heptafluorobutyryl derivative was formed for the analysis of glycerol in plasma and VLDL-TG, the N-heptafluorobutyryl n-propyl ester derivative was used for leucine in VLDL-apoB-100, and the $t$-butyldimethylsilyl ( $t$-BDMS) derivative was used for free leucine in plasma.

\section{Calculations}

Estimated glomerular filtration rate was calculated by using the four-component Modification of Diet in Renal Disease (MDRD) Study equation [17]. Creatinine clearance rate was calculated by dividing the product of urine creatinine concentration (in milligrams per milliliter) $\times 24$-hour volume (in milliliters) by serum creatinine concentration (in milligrams per milliliter).

The fractional turnover rates (FTR) of VLDL-TG and VLDL-apoB-100 were determined by fitting the glycerol and leucine TTR time courses in plasma and in VLDL-TG and VLDL-apoB-100, respectively, to a multicompartmental model as previously described $[10,11,15]$. The hepatic secretion rates of VLDLTG (in micromoles per liter of plasma per minute) and VLDL-apoB-100 (in nanomoles per liter of plasma 


\section{CardioRenal Medicine}

\begin{tabular}{l|l}
\hline \multicolumn{2}{l}{ Cardiorenal Med 2012;2:57-65 } \\
\hline DOI: 10.1159/000335509 & $\begin{array}{l}\text { @ 2012 S. Karger AG, Basel } \\
\text { www.karger.com/crm }\end{array}$ \\
\hline
\end{tabular}

Wang et al.: VLDL Metabolism and Renal Failure

Table 1. Sex, age and body composition of the study subjects

\begin{tabular}{|c|c|c|c|c|}
\hline & \multicolumn{2}{|l|}{ CKD-ND } & \multicolumn{2}{|l|}{ CKD-PD } \\
\hline & $\begin{array}{l}\text { control } \\
(\mathrm{n}=12)\end{array}$ & $\begin{array}{l}\text { CKD } \\
(n=6)\end{array}$ & $\begin{array}{l}\text { control } \\
(\mathrm{n}=12)\end{array}$ & $\begin{array}{l}\text { CKD } \\
(n=6)\end{array}$ \\
\hline Male/female & $6 / 6$ & $3 / 3$ & $6 / 6$ & $3 / 3$ \\
\hline Age, years & $44.5 \pm 1.7$ & $47.7 \pm 3.9$ & $38.2 \pm 4.0$ & $42.5 \pm 7.2$ \\
\hline Body mass index & $30.3 \pm 1.4$ & $28.0 \pm 2.0$ & $25.8 \pm 1.6$ & $24.0 \pm 1.8$ \\
\hline Fat-free mass, $\mathrm{kg}$ & $60.3 \pm 3.3$ & $60.5 \pm 6.9$ & $53.1 \pm 3.0$ & $48.9 \pm 3.7$ \\
\hline Body fat, $\%$ body weight & $32.3 \pm 2.6$ & $30.3 \pm 3.2$ & $27.9 \pm 3.3$ & $29.4 \pm 4.1$ \\
\hline
\end{tabular}

Values are means \pm SEM or numbers.

per minute) into plasma, which represent the amounts of VLDL-TG and VLDL-apoB-100 (i.e. VLDL particles) secreted by the liver per unit of plasma, were calculated by multiplying the FTR of VLDL-TG and VLDL-apoB-100 (in pools per minute) by the concentrations of VLDL-TG (in micromoles per liter) and VLDL-apoB-100 (in nanomoles per liter) in plasma, respectively [10, 11, 15]. The mean residence times (MRT) of VLDL-TG and VLDL-apoB-100, which represents the time VLDL-TG and VLDL-apoB-100 spend in the circulation after secretion by the liver, was calculated as 1/FTR. The palmitate rate of appearance in plasma was calculated by dividing the palmitate tracer infusion rate by the average plasma palmitate TTR values between 60 and $240 \mathrm{~min}$.

The homeostasis model assessment of insulin resistance (HOMA-IR) score, an index of whole-body insulin resistance, was calculated by multiplying the plasma concentrations of insulin (in microunits per milliliter) and glucose (in millimoles per liter) and then dividing this value by 22.5 [18].

\section{Statistical Analyses}

For normally distributed variables, data are presented as means \pm SEM and Student's t test was used to evaluate differences between subjects with CKD-ND and their controls and subjects with CKD-PD and their controls. For non-normally distributed variables, data are presented as median and quartiles and data were log transformed for analysis; Mann-Whitney $U$ test was used for those that failed to be normally distributed after log transformation. All analyses were performed using SAS software version 9.1 (SAS Institute, Cary, N.C., USA). A p value of $\leq 0.05$ was considered statistically significant.

\section{Results}

\section{Characteristics of the Study Subjects}

The estimated glomerular filtration rate was $22.2 \pm 3.3 \mathrm{ml} / \mathrm{min} / 1.73 \mathrm{~m}^{2}$ in subjects with CKD-ND. Creatinine clearance rate and 24-hour urine volume were $34 \pm 6 \mathrm{ml} / \mathrm{min}$ and 2.4 \pm 0.3 liters in subjects with CKD-ND and $6.6 \pm 2.4 \mathrm{ml} / \mathrm{min}$ and $0.5 \pm 0.2$ liters in subjects with CKD-PD.

Subjects with CKD-ND and CKD-PD and their corresponding control subjects were matched on sex, age, BMI and body composition (table 1). Serum creatinine and urea nitrogen concentrations were significantly greater in CKD-ND and CKD-PD than their respective control subjects (all $\mathrm{p}<0.05$; table 2). Mean plasma glucose concentration was not different between subjects with CKD-ND and subjects of their corresponding control group but was lower in subjects with CKD-PD than in subjects of their control group $(p=0.025)$. Nonetheless, plasma insulin concentration and HOMA-IR score were not different between subjects with CKD-ND and CKD-PD and their corresponding control groups (table 1). Plasma free fatty acid, total cholesterol and LDL-cholesterol concentrations were not different be- 


\section{CardioRenal Medicine}

\begin{tabular}{l|l}
\hline Cardiorenal Med 2012;2:57-65 \\
\hline DOI: 10.1159/000335509 & $\begin{array}{l}\text { @ 2012 S. Karger AG, Basel } \\
\text { www.karger.com/crm }\end{array}$ \\
\hline
\end{tabular}

Wang et al.: VLDL Metabolism and Renal Failure

Table 2. Serum creatinine, blood urea nitrogen and plasma insulin, glucose and lipid concentrations

\begin{tabular}{lccccc}
\hline & \multicolumn{2}{c}{ CKD-ND } & & & \multicolumn{2}{l}{ CKD-PD } & \\
\cline { 2 - 3 } \cline { 5 - 6 } & control & CKD & & control & CKD \\
\hline Creatinine, mg/dl & $0.8 \pm 0.1$ & $3.3 \pm 0.4^{* *}$ & & $0.8 \pm 0.1$ & $8.9 \pm 1.3^{* *}$ \\
Urea nitrogen, mg/dl & $14.5 \pm 1.4$ & $52.7 \pm 11.2^{*}$ & & $15.0(14.5,17.5)$ & $55.0(49.0,66.3)^{* *}$ \\
Insulin, $\mu \mathrm{U} / \mathrm{ml}$ & $10.8 \pm 2.6$ & $9.6 \pm 1.9$ & & $8.7 \pm 1.5$ & $8.0 \pm 2.2$ \\
Glucose, $\mathrm{mg} / \mathrm{dl}$ & $93 \pm 2$ & $97 \pm 3$ & & $94 \pm 2$ & $86 \pm 4^{*}$ \\
HOMA-IR score & $2.5 \pm 0.6$ & $2.4 \pm 0.5$ & & $2.1 \pm 0.4$ & $1.7 \pm 0.5$ \\
Free fatty acids, $\mu \mathrm{mol} / \mathrm{l}$ & $423(314,491)$ & $475(433,527)$ & & $383(305,536)$ & $407(376,443)$ \\
Total cholesterol, mg/dl & $175 \pm 7$ & $191 \pm 4$ & & $159 \pm 8$ & $164 \pm 17$ \\
LDL cholesterol, mg/dl & $96 \pm 6$ & $118 \pm 6$ & & $91 \pm 8$ & $89 \pm 16$ \\
HDL cholesterol, mg/dl & $45(41,74)$ & $43(34,47)$ & & $49 \pm 3$ & $34 \pm 3^{*}$ \\
Total TG, mg/dl & $115 \pm 20$ & $124 \pm 26$ & & $93 \pm 6$ & $203 \pm 33^{* *}$ \\
VLDL-TG, mg/dl & $64 \pm 11$ & $77 \pm 20$ & & $42 \pm 7$ & $138 \pm 27^{* *}$ \\
VLDL-apoB-100, mg/dl & $42 \pm 7$ & $56 \pm 11$ & & $32 \pm 5$ & $96 \pm 23^{* *}$ \\
\hline
\end{tabular}

Values are means \pm SEM or medians (quartiles). *Value is significantly different from that of the corresponding control group; $\mathrm{p}<0.05$. $^{* *}$ Value is significantly different from that of the corresponding control group; $\mathrm{p}<0.005$.

tween CKD-ND or CKD-PD and their control subjects (table 2). HDL cholesterol concentration was not different between CKD-ND and control subjects, but was $\sim 30 \%$ less in CKD-PD than their control subjects $(\mathrm{p}<0.01)$. Total plasma TG, VLDL-TG and VLDLapoB-100 concentrations were $10-30 \%$ greater in subjects with CKD-ND than in control subjects, but the differences did not reach statistical significance at the $\mathrm{p}<0.05$ level (table 2 ). Total plasma TG, VLDL-TG, and VLDL-apoB-100 concentrations in subjects with CKD-PD were more than double the corresponding values in control subjects (all $p \leq 0.001$; table 2 ).

\section{Lipid Kinetics}

The palmitate rate of appearance into plasma was not different between CKD-ND and control subjects $(1.1 \pm 0.1$ and $1.3 \pm 0.1 \mu \mathrm{mol} / \mathrm{kg}$ fat-free mass $/ \mathrm{min}$, respectively) or CKD$\mathrm{PD}$ and control subjects ( $1.1 \pm 0.1$ and $1.3 \pm 0.2 \mu \mathrm{mol} / \mathrm{kg}$ fat-free mass $/ \mathrm{min}$, respectively).

The secretion rates of VLDL-TG and VLDL-apoB-100 into plasma were not different between subjects with CKD-ND or CKD-PD and their respective control groups (fig. 1). Consequently, the molar ratio of VLDL-TG to VLDL-apoB-100 secretion rates was also not different between CKD-ND and control subjects (11,456 $\pm 2,003$ and 15,546 $\pm 3,528$, respectively) or CKD-PD and control subjects (16,925 $\pm 1,929$ and 17,526 $\pm 3,948$, respectively). The MRT of VLDL-TG tended to be greater $(\mathrm{p}=0.07)$ in CKD-ND than control subjects (fig. 1 ) and was two-fold greater in CKD-PD than control subjects ( $\mathrm{p}=0.006$; fig. 1 ). The MRT of VLDLapoB-100 in plasma tended to be greater in CKD-ND than control subjects $(\mathrm{p}=0.06)$ and was more than two-fold greater ( $\mathrm{p}=0.001$ ) in CKD-PD than their control subjects (fig. 1).

\section{Discussion}

Hypertriglyceridemia is a common feature of CKD [1] and an important risk factor for coronary heart disease [19], which is the major cause of mortality in patients with CKD [2]. In the present study, we evaluated lipoprotein kinetics in subjects with stage 3 and 4 CKD 


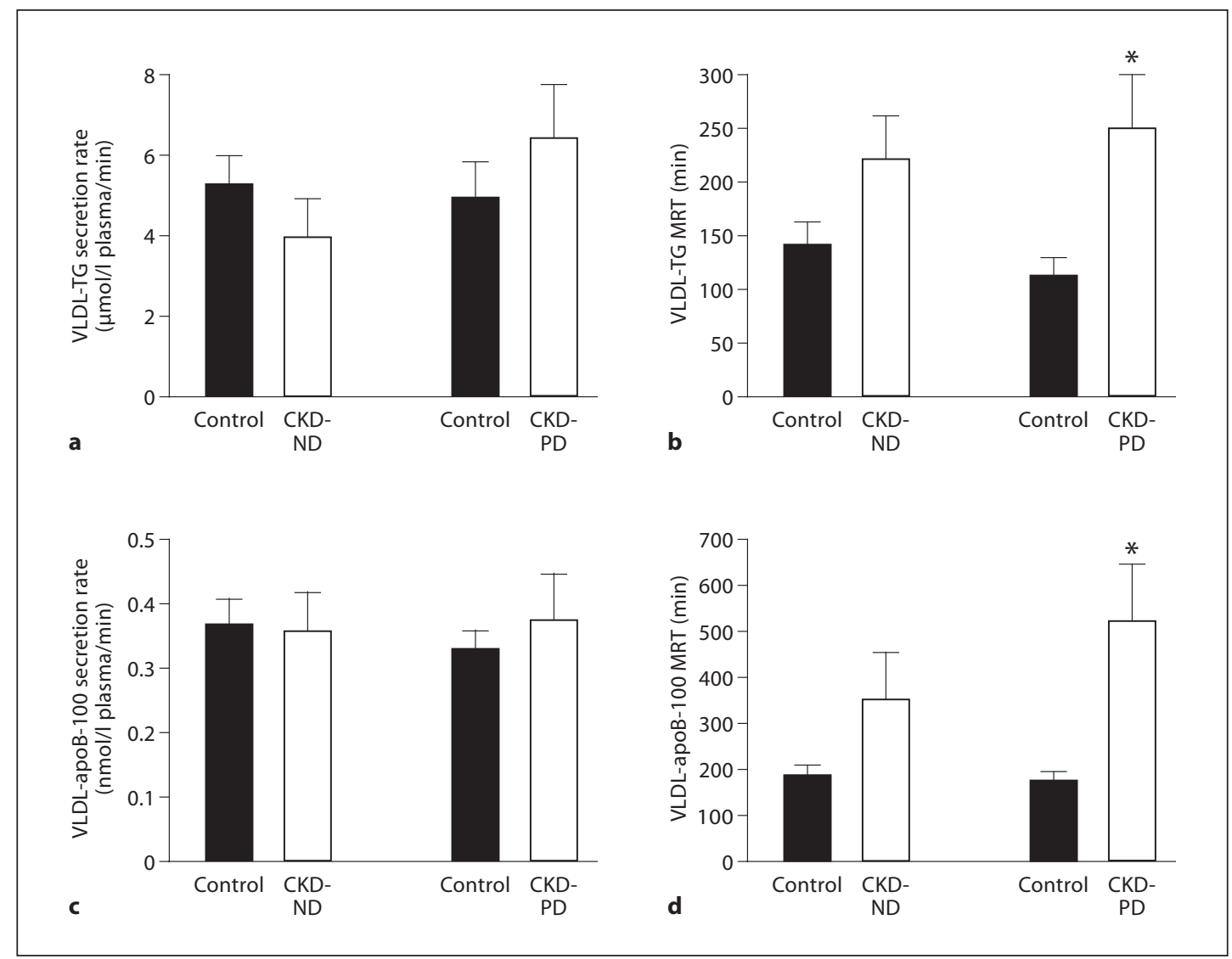

Fig. 1. VLDL-TG secretion rates (a) and mean residence time (MRT) in plasma (b) and VLDL-apoB-100 secretion rates (c) and MRT in plasma (d) in subjects with CKD who were not receiving dialysis (CKD-ND) and subjects with CKD who required dialysis (CKD-PD) and healthy sex-, age-, and BMI-matched control subjects. Values are means \pm SEM. ${ }^{*}$ Value is significantly different from that of the corresponding control group; $\mathrm{p} \leq 0.01$.

and in subjects with stage $5 \mathrm{CKD}$ receiving peritoneal dialysis to determine the metabolic mechanisms responsible for the increase in plasma TG. Our data demonstrate that impaired plasma clearance of VLDL-TG and VLDL-apoB-100 is the major abnormality accounting for hypertriglyceridemia in CKD. Moreover, the impairment in VLDL-TG and VLDL-apoB-100 plasma clearance tended to be more pronounced in stage $5 \mathrm{CKD}$ than in less severe stage 3 and $4 \mathrm{CKD}$, which helps explain the gradual increase in plasma TG concentrations associated with progressive renal deterioration [3].

The mechanisms responsible for the impaired plasma clearance of VLDL-TG and VLDLapoB-100 in subjects with CKD are likely multifactorial. Data from studies conducted in both rodents and patients have shown CKD is associated with a decrease in plasma, adipose tissue and muscle lipase activities [20-22], which regulate the catabolism of circulating TG. However, there is no direct correlation between plasma TG concentration and lipase activity in rodent models or renal disease [20], suggesting that the increase in TG concentration is not simply a function of a decrease in lipase action. Several factors might contribute to the absence of an association between serum TG clearance and measured lipase activity. First, it is possible that the assessment of tissue lipase activity, which involves measuring $\mathrm{V}_{\max }$ ex vivo or post-heparin plasma lipase activity, does not provide a reliable measure of actual enzyme 


\section{CardioRenal Medicine}

Cardiorenal Med 2012;2:57-65

DOI: 10.1159/000335509

Wang et al.: VLDL Metabolism and Renal Failure

activity in vivo. Second, VLDL-apoB-100, which provides the structural framework for TG incorporation, has considerable capacity to accumulate TG $[23,24]$. The TG content of nascent VLDL particles secreted by the liver can influence intravascular VLDL metabolism because larger, TG-rich particles are more susceptible to lipolysis by lipoprotein lipase than smaller particles $[25,26]$. However, we found no difference in the relative secretion rates of VLDL-TG and VLDL-apoB-100 between subjects with CKD and healthy control subjects, which suggests that, on average, the TG content of nascent VLDL was not increased in the CKD group. Third, the availability of apoC-I, apoC-II, apoC-III, and apoE, which are added to VLDL during assembly in the liver or are transferred to VLDL from HDL in the circulation, can affect the lipolytic activity [27-31], and a relative deficiency in apoC-II and increase in apoC-I and apoC-III has been reported in VLDL of subjects with CKD [31-33]. In addition, the kidney expresses both lipoprotein lipase and VLDL receptor $[34,35]$; therefore, CKD may affect the clearance of VLDL-TG and VLDL particles directly.

Although we did not find an increased secretion of VLDL particles or VLDL-TG in subjects with CKD, other investigators have reported an increase in VLDL-TG and VLDLapoB-100 secretion in addition to impaired plasma VLDL-TG and VLDL-apoB-100 clearance in subjects with CKD $[4,5,8,9]$. The reasons for this discrepancy are not entirely clear but could be due to the fact that VLDL-TG and VLDL-apoB-100 secretion rates in the studies that report overproduction of VLDL-TG and VLDL-apoB-100 in CKD used estimates of plasma volume for healthy subjects to calculate secretion rates (i.e. FTR $\times$ plasma concentration $\times$ plasma volume), which can be unreliable in subjects with CKD. We avoided this potential bias by calculating hepatic VLDL-TG and VLDL-apoB-100 secretion rates per unit of plasma (i.e. FTR $\times$ plasma concentration) and obtained results that are consistent with those from a study in which plasma volume was directly measured in all study subjects (i.e. those with CKD and healthy controls) [6]. It is also possible that we did not detect a difference in hepatic secretion of VLDL-TG and VLDL-apoB-100 in our subjects with CKD and their controls because there is evidence that only the secretion of large VLDL (VLDL1) but not the secretion of small VLDL (VLDL2) is affected by CKD [9].

It is possible that we failed to observe a significant effect of CKD on hepatic VLDL-TG and VLDL-apoB-100 secretion and/or a significant effect of CKD-ND on VLDL-TG and VLDL-apoB-100 MRT because of a statistical type 2 error, due to the small number of subjects. However, based on the reproducibility of VLDL-TG and VLDL-apoB-100 kinetic and concentration measurements in our laboratory $[10,36]$, our study was adequately powered (80\%) to detect a $25-35 \%$ difference in VLDL-apoB-100 and VLDL-TG secretion rates.

In summary, the results from our study demonstrate that hypertriglyceridemia in CKD is due to impaired plasma clearance and not hepatic hypersecretion of VLDL-TG and VLDLapoB-100. These data suggest that medications or lifestyle changes that increase VLDL-TG clearance from plasma might be a particularly useful therapeutic approach for treating hypertriglyceridemia in this patient population.

\section{Acknowledgements}

This study was supported by US National Institutes of Health grants DK37948, HD57796, AG31297, DK56341 (Nutrition and Obesity Research Center), RR00954 (Biomedical Mass Spectrometry Resource), and RR24992 (Washington University Clinical and Translational Science Award).

\section{Disclosure Statement}

None of the authors has any relevant conflicts of interest. 


\section{CardioRenal Medicine}

Cardiorenal Med 2012;2:57-65

\begin{tabular}{l|l}
\hline DOI: $10.1159 / 000335509$ & @ 2012 S. Karger AG, Basel
\end{tabular}
www.karger.com/crm

Wang et al.: VLDL Metabolism and Renal Failure

\section{References}

1 Vaziri ND: Dyslipidemia of chronic renal failure: the nature, mechanisms, and potential consequences. Am J Physiol Renal Physiol 2006;290:F262-F272.

$\longrightarrow 2$ Tonelli M, Wiebe N, Culleton B, House A, Rabbat C, Fok M, McAlister F, Garg AX: Chronic kidney disease and mortality risk: a systematic review. J Am Soc Nephrol 2006;17:2034-2047.

-3 Attman PO, Tavella M, Knight-Gibson C, Samuelsson O, Alaupovic P: Apolipoprotein B-containing lipoprotein particles in progressive renal insufficiency. Contrib Nephrol 1992;98:11-19.

4 Cramp DG, Tickner TR, Beale DJ, Moorhead JF, Wills MR: Plasma triglyceride secretion and metabolism in chronic renal failure. Clin Chim Acta 1977;76:237-241.

5 Verschoor L, Lammers R, Birkenhäger JC: Triglyceride turnover in severe chronic non-nephrotic renal failure. Metabolism 1978;27:879-883.

6 Savdie E, Gibson JC, Crawford GA, Simons LA, Mahony JF: Impaired plasma triglyceride clearance as a feature of both uremic and posttransplant triglyceridemia. Kidney Int 1980;18:774-782.

$\checkmark$ Chan DT, Dogra GK, Irish AB, Ooi EM, Barrett PH, Chan DC, Watts GF: Chronic kidney disease delays VLDLapoB-100 particle catabolism: potential role of apolipoprotein C-III. J Lipid Res 2009;50:2524-2531.

8 Warwick GL, Packard CJ, Demant T, Bedford DK, Boulton-Jones JM, Shepherd J: Metabolism of apolipoprotein Bcontaining lipoproteins in subjects with nephrotic-range proteinuria. Kidney Int 1991;40:129-138.

-9 Prinsen BHCMT, Rabelink TJ, Romijn JA, Bisschop PH, de Barse MMJ, de Boer J, van Haeften TW, Barrett PHR, Berger R, de Sain-van der Velden MGM: A broad-based metabolic approach to study VLDL apoB100 metabolism in patients with ESRD and patients treated with peritoneal dialysis. Kidney Int 2004;65:1064-1075.

10 Magkos F, Patterson BW, Mittendorfer B: Reproducibility of stable isotope-labeled tracer measures of VLDL-triglyceride and VLDL-apolipoprotein B-100 kinetics. J Lipid Res 2007;48:1204-1211.

11 Mittendorfer B, Patterson BW, Klein S: Effect of weight loss on VLDL-triglyceride and apoB-100 kinetics in women with abdominal obesity. Am J Physiol Endocrinol Metab 2003;284:E549-E556.

12 Patterson BW, Zhao G, Elias N, Hachey DL, Klein S: Validation of a new procedure to determine plasma fatty acid concentration and isotopic enrichment. J Lipid Res 1999;40:2118-2124.

13 Magkos F, Patterson BW, Mittendorfer B: No effect of menstrual cycle phase on basal very-low-density lipoprotein triglyceride and apolipoprotein B-100 kinetics. Am J Physiol Endocrinol Metab 2006;291:E1243-E1249.

14 Magkos F, Patterson BW, Mohammed BS, Klein S, Mittendorfer B: Women produce fewer but triglyceride-richer very low-density lipoproteins than men. J Clin Endocrinol Metab 2007;92:1311-1318.

15 Patterson BW, Mittendorfer B, Elias N, Satyanarayana R, Klein S: Use of stable isotopically labeled tracers to measure very low density lipoprotein-triglyceride turnover. J Lipid Res 2002;43:223-233.

16 Patterson BW, Zhang XJ, Chen Y, Klein S, Wolfe RR: Measurement of very low stable isotope enrichments by gas chromatography/mass spectrometry: application to measurement of muscle protein synthesis. Metabolism 1997;46:943948.

17 Levey AS, Coresh J, Greene T, Marsh J, Stevens LA, Kusek JW, Van Lente F; Chronic Kidney Disease Epidemiology Collaboration: Expressing the modification of diet in renal disease study equation for estimating glomerular filtration rate with standardized serum creatinine values. Clin Chem 2007;53:766-772.

18 Matthews DR, Hosker JP, Rudenski AS, Naylor BA, Treacher DF, Turner RC: Homeostasis model assessment: insulin resistance and beta-cell function from fasting plasma glucose and insulin concentrations in man. Diabetologia 1985; 28:412-419.

19 Goldberg IJ, Eckel RH, McPherson R: Triglycerides and heart disease. Arterioscler Thromb Vasc Biol 2011;31:17161725 .

20 Kraemer FB, Chen YD, Reaven GM: Hypertriglyceridemia and lipoprotein lipase activity in experimental uremia. Nephron 1982;30:274-278.

21 Mordasini R, Frey F, Flury W, Klose G, Greten H: Selective deficiency of hepatic triglyceride lipase in uremic patients. N Engl J Med 1977;297:1362-1366.

22 Sato T, Liang K, Vaziri ND: Down-regulation of lipoprotein lipase and VLDL receptor in rats with focal glomerulosclerosis. Kidney Int 2002;61:157-162.

-23 Steiner G, Poapst ME, Shumak SL, Foster DM: Metabolism of the apolipoprotein B-containing lipoproteins. Methods Enzymol 1986;129:395-420.

24 Gibbons GF, Wiggins D, Brown AM, Hebbachi AM: Synthesis and function of hepatic very-low-density lipoprotein. Biochem Soc Trans 2004;32:59-64.

25 Fisher RM, Coppack SW, Humphreys SM, Gibbons GF, Frayn KN: Human triacylglycerol-rich lipoprotein subfractions as substrates for lipoprotein lipase. Clin Chim Acta 1995;236:7-17.

26 Breckenridge WC: The catabolism of very low density lipoproteins. Can J Biochem Cell Biol 1985;63:890-897.

27 Converse CA, Skinner RE: Lipoprotein Analysis: A Practical Approach. New York, Oxford University Press, 1992.

28 Mead J, Irvine S, Ramji D: Lipoprotein lipase: structure, function, regulation, and role in disease. J Mol Med 2002;80: 753-769.

-29 Shachter NS: Apolipoproteins C-I and C-III as important modulators of lipoprotein metabolism. Curr Opin Lipidol 2001;12:297-304. 


\section{CardioRenal Medicine}

\begin{tabular}{l|l}
\hline Cardiorenal Med 2012;2:57-65 & $\begin{array}{l}\text { @ 2012 S. Karger AG, Basel } \\
\text { www.karger.com/crm }\end{array}$ \\
\hline DOI: 10.1159/000335509
\end{tabular}

Wang et al.: VLDL Metabolism and Renal Failure

-30 Chappell DA, Medh JD: Receptor-mediated mechanisms of lipoprotein remnant catabolism. Prog Lipid Res 1998;37: 393-422.

-31 Kaysen GA: Dialysis removes apolipoprotein C-I, improving very low-density lipoprotein clearance. Kidney Int 2007; 72:779-781.

-32 Atger V, Beyne P, Frommherz K, Roullet JB, Drueke T: Presence of Apo B48, and relative Apo CII deficiency and Apo CIII enrichment in uremic very-low density lipoproteins. Ann Biol Clin (Paris) 1989;47:497-501.

-33 Arnadottir M, Dallongeville J, Fruchart JC, Nilsson-Ehle P: Very-low-density lipoprotein of uremic patients is a poor substrate for bovine lipoprotein lipase in vitro. Metabolism 1996;45:686-690.

- 34 Ruge T, Neuger L, Sukonina V, Wu G, Barath S, Gupta J, Frankel B, Christophersen B, Nordstoga K, Olivecrona T, Olivecrona G: Lipoprotein lipase in the kidney: activity varies widely among animal species. Am J Physiol Renal Physiol 2004;287:F1131-F1139.

-35 Quaschning T, Koniger M, Kramer-Guth A, Greiber S, Pavenstadt H, Nauck M, Schollmeyer P, Wanner C: Receptormediated lipoprotein uptake by human glomerular cells: comparison with skin fibroblasts and HepG2 cells. Nephrol Dial Transplant 1997;12:2528-2536.

36 Magkos F, Fabbrini E, Korenblat K, Okunade AL, Patterson BW, Klein S: Reproducibility of glucose, fatty acid and VLDL kinetics and multi-organ insulin sensitivity in obese subjects with non-alcoholic fatty liver disease. Int J Obes 2011;35:1233-1240. 